\title{
Finite Element Analysis and Optimization of Electro Hydraulic Servo Valve
}

\author{
Akhil Deshpande \\ Department of Mechanical Engineering \\ KLS's Gogte Institute of Technology, Belagavi, Karnataka, India \\ Naveen Junja \\ Department of Mechanical Engineering \\ KLS's Gogte Institute of Technology, Belagavi, Karnataka, India
}

\begin{abstract}
In every industry the source of power is supplied through mechanical, electrical or through fluid power. Compared to electrical power and mechanical power the fluid power is most suitable. Now a days in majority of the industries, the hydraulic power is used widely as the source of power. The hydraulic applications make way into, from basic agricultural field to advanced aerospace industries. Fluid power control is developed by increasing the parameters like mass, power, high speed and greater accuracy. In some applications like automatic fire control, machine tools, and flight control it is needed to achieve the faster control at high power levels, so this can be done by combination of hydraulic servo mechanics and electronic signal process. In electronic field it is easier to generate, transduce and process the signal than in the mechanical and fluid signals. The electro hydraulic servo mechanics provide more efficient, more reliable and faster devices. The electro hydraulic servo valve is the main component in this mechanism that accurately controls the flow of liquid in hydraulic system. The analysis and optimization of the valve has been done with the help of ANSYS software. Valve is designed and checked properly to achieve the requirements. Before optimization the mass of the valve was $141.81 \mathrm{gm}$ and after optimization the mass of the valve is reduced to $72.77 \mathrm{gm}$. Optimization is done by removing the excess material in the valve. After optimization we got maximum stress induced in the valve is $34.434 \mathrm{MPa}$ which is less than the yield stress (310MPa) of the material. In addition decrease in size of valve leads to failure of the component, large deformations are induced. The total weight reduced is $69.04 \mathrm{gm}$. Hence the cost is saved by Rs 310680 per year.
\end{abstract}

Keywords - maximum deformation, maximum stress, and optimization

\section{INTRODUCTION}

Fluid power control developed with increasing the quantities or parameters like mass, power, high speed and greater accuracy. In some industries or areas like automatic fire control, machine tools, and in flight control it need to achieve the and faster control at high power levels, so this can be done by combination of hydraulic servo mechanics and electronic signal process. In electronic field it is easier to generate, transduce and process the signal than the mechanical and fluid signals. The electro hydraulic servo mechanics provides more efficient, more reliable and faster devices. The electro hydraulic servo valve is the main component in this mechanism, it is also called as forward loop amplifier and electrical to hydraulic transducer. Servo valves these are devices, which control the flow of liquid in response of ( respect to ) electrical input signal and also in some machines and devices it control the forces, velocity, pressure, position ( through the piston or cylinder ). In electro hydraulic control system, the connection between electric and hydraulic is done by hydraulic servo valves. Hydraulic servo valves are main element in the hydraulic system. Servo valves control the pressure and flow of fluid by converting electrical signal to motion of the valve and it is closed loop control system

Electro hydraulic servo valves have wide range of applications in automobiles, aircraft, manufacturing systems, robotics, ships, flight simulation etc. These systems provide the high force, quick response, high power and weight ratio and good control. Servo hydraulic systems are called as self-cooled because it carried out the heat away from the flow control component and actuator by effectively operating the fluid.

\section{ANALYSIS MATERIALS AND METHODS}

A. Material

The term ductile iron it is also called nodular cast iron, spheroidal graphite iron. This ductile iron is discovered by 'Keith mills'. Ductile iron consists of nodular graphite hence it improves the fatigue resistance and impact. Basically 
ductile iron involves number of substances or materials, it does not contains a single substance or material. Hence different characteristics can be manufactured by arranging the microstructure. The general property of this material is depends on the form of graphite and it is in the type of nodules. In grey cast iron the graphite is present in kind of flakes. The nodules form of graphite is obtained by including the nodulizing ingredients (they are magnesium, tellurium, cerium etc).

The ductile cast iron is created by adding particular alloy and suitable cooling, so the carbon is transformed into spherical forms. At the stage of solidification the nodules are produced. Ductile iron has good mechanical characteristics than the steel. Ductile iron and Austempered ductile iron have same kind of graphite like spherical or nodular but the Austempering has different matrix (it is mixture of stable austenite and bainite.

Chemical composition of ductile iron is as follows,

$>3.2$ to 3.6 percentage of carbon element.

$>0.1$ to 0.2 percentage of manganese element.

$>2.2$ to 2.8 percentage of silicon element.

$>0.005$ to 0.02 percentage of sulfur element.

$>0.03$ to 0.04 percentage of magnesium element.

$>0.005$ to 0.04 percentage of phosphorous element.

$>$ Copper element less than 0.04 percentages.

$>$ Iron.

1) Structure - The ductile iron has homogeneous structure (means grains are in close form) so it has good wear resistance and machine ability. It has capacity to hold up the high pressure (pneumatic and hydraulic pressure).

2) Thermal conductivity - The ductile iron excellent thermal conductivity because the graphite is good heat conductor. (31 to $36 \frac{w}{m-k}$ )

3) Corrosion resistance - Compared to steels it has good corrosion resistance.

4) Machinability - The micro structure of ductile iron consists of graphite hence its machinability is excellent and chip creation is easy.

5) Hardness - The ductile iron has low hardness because of existence of graphite in its microstructure.

6) Modulus of elasticity- The ductile materials have proportional to stress - strain limit. The modulus elasticity of ductile material is changes from 162 to $170 \mathrm{GPa}$.

7) Casting - It is easy to cast because ductile material has high flexibility and also it does not requires any high cost dies and patterns, there is no limitation to the design.

8) Tensile strength - It has high tensile strength which is varies from $414 \mathrm{MPa}$ (ferriticgrade) to $1380 \mathrm{MPa}$ ( formartensitic grade).

9) Density - Ductile iron has lesser density and it is varies from 7.1 to $7.2 \mathrm{~g} / \mathrm{cm}^{3}$.

Other properties

$>$ Elongation break is at $=2$ to $19 \%$

Fracture toughness $=14$ to $30 \mathrm{Mpa}-\sqrt{m}$

$>$ Poisson's ratio $=0.28$ to 0.29

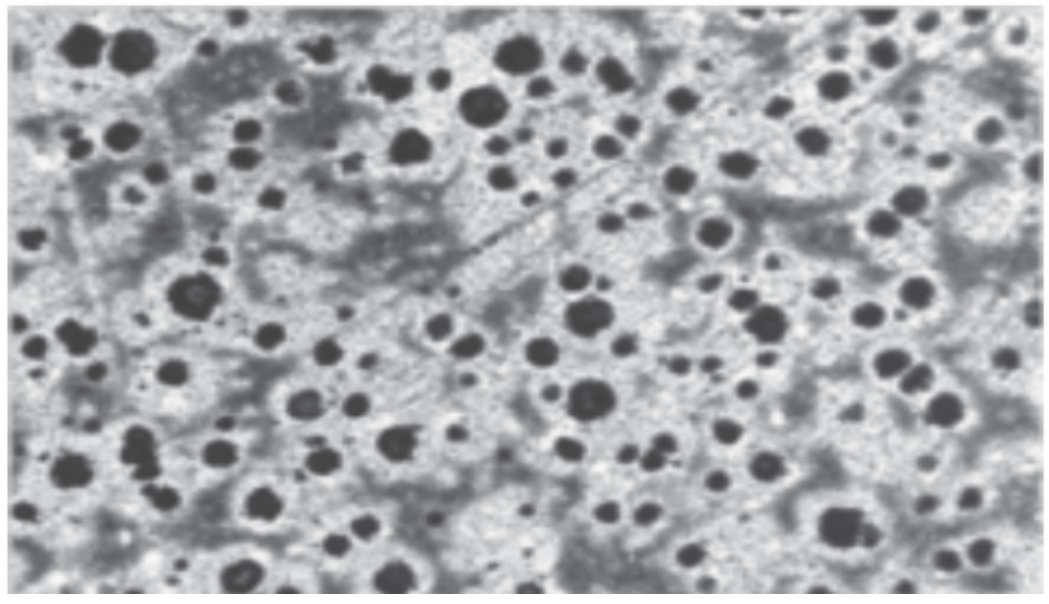

Figure 1 Microstructure of ductile iron 


\section{B. Properties of Ductile Iron}

Table -1 properties of Ductile Iron

\begin{tabular}{|l|l|}
\hline Elastic modulus & $160-170 \mathrm{MPa}$ \\
\hline Poisson's ratio & 0.28 to 0.29 \\
\hline Tensile strength & $414-1380 \mathrm{MPa}$ \\
\hline Yield strength & $310 \mathrm{MPa}$ \\
\hline Mass density & $7.1-7.2 \mathrm{~g} / \mathrm{cm}^{3}$ \\
\hline
\end{tabular}

C. Finite element analysis

Finite element method or finite element analysis is defined as it is a numerical or computational method which is used for to determine the approximate solutions to boundary value problems for partial differential equation. The term finite element means, it subdivide the large problem into small finite parts these finite parts are called as finite elements. Finite element method provides simple equations for these finite elements and makes the large equation for entire system by combining these simple equations. It provides approximate solution by reducing error in function, for this it uses the variation methods. This method used to solve the problems in engineering field and solve the problems which are associated with complicated loadings, geometries and material properties.

The subdivision of entire system into small finite elements has some advantages,

$>$ Complex geometry of the system can be representing precisely or accurately.

$>$ The whole solution of the system can be representing easily.

$>$ It includes dissimilar material properties.

This method consists of dividing a domain problem into number of sub domains, each sub domain includes of set of simple equations. The global equation of the system can be obtained by assembling these set of elemental or simple equation. These simple equations are called as partial differential equations. Finite element method normally uses the Galerkin method for this process. Galerkin method is defined as it is mathematical process of integration of product of weight and residual functions and integration is set to zero. This method reduces the errors in approximation by using trail function in partial differential equation. It removes the spatial derivatives from the partial differential equation, estimate this with algebraic equations and ordinary differential equations. In steady state problems algebraic equations are generated, and these are solved by using the numerical linear algebra techniques. In transient problems ordinary differential equations occurs, and these are solved by using numerical integration methods like Euler's method and Rungekutta method. The global equation is obtained from simple or elemental equation by conversion of coordinates from the local nodes of sub domain to domain global nodes. And this process is done by FEM software using coordinates data which is obtained from sub domains.

ANSYS it is finite element software and this helps to divide the complicated structure into small parts called as elements. ANSYS software applies the equations, that control over the nature of elements and solves these elements. This software is used for design and optimization of complex problems. The structure which is solving in this software usually it is complex in geometry, loads and governing equations. ANSYS is not only used in mechanical section it is also used in civil, chemistry, physics and electrical department. ANSYS software gives cost effective to investigate the performance of product and this kind of product is called as virtual prototype or model. Using this virtual prototype the designer can produce different models and optimize the item before it is going to manufacture. So ANSYS reduces the risk and cost of the design of product. The software helps designer to observe the effect of design on total nature of the product.

\section{CALCULATION AND RESULTS}

Diameter of the port, $\mathrm{D}=3 \mathrm{~mm}$

Center to center distance between ports, $\mathrm{Cc}=7.85 \mathrm{~mm}$

Pressure applied, $\mathrm{P}=210$ bar

$=210 \times 9.81 \times 10^{-3}$

$=20.601 \mathrm{~N} / \mathrm{mm}^{2}$

Thickness of the valve, $\mathrm{t}=\mathrm{Cc}-\mathrm{D}$

$=7.85-3$

$=4.85 \mathrm{~mm}$

$\mathrm{D} / \mathrm{t}=3 / 4.5=0.61<10$

The ratio is less than 10 hence it is thick cylinder. 
Using Lamias equation applied to the thick cylinder

Tangential stress developed in valve $=P \frac{\left(\mathrm{r}_{0}{ }^{2}+\mathrm{r}_{1}{ }^{2}\right)}{\left(\mathrm{r}_{0}{ }^{2}-\mathrm{r}_{1}{ }^{2}\right)}=20.61 \frac{\left(4.85^{2}+1.5^{2}\right)}{\left(4.85^{2}-1.5^{2}\right)}=\frac{530.93}{21.27}=24.96 \mathrm{~N} / \mathrm{mm}^{2}$

\section{IV.ANALYSIS AND RESULTS}

\section{A. Analysis of valve before optimization}

\section{Create the model}

The model is created in ANSYS software, it is the initial step. Using preprocessor apply the material properties, type of element, real constants and dimensions of the valve. Mass of the valve is $141.81 \mathrm{gm}$

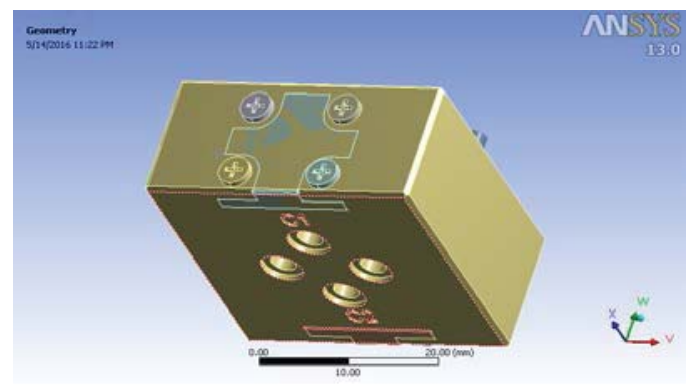

Figure 2 Model view of the valve

\section{Meshing}

In this step the created model is dividing into number of elements. This is the main stage in analysis and it influences the accuracy of analysis. Solid 186 element is used for mesh the valve and free meshing is applied on the model.

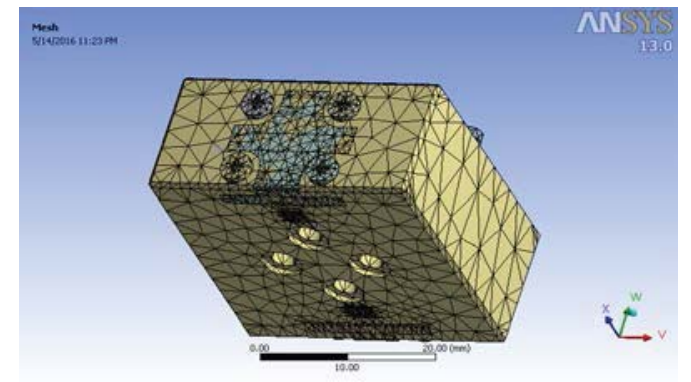

Figure 3 Meshing of the model

\section{Boundary condition}

For the large frequency analysis of finite element model it requires the boundary conditions. After applying the boundary conditions, the model does not depend on the meshing of the element.

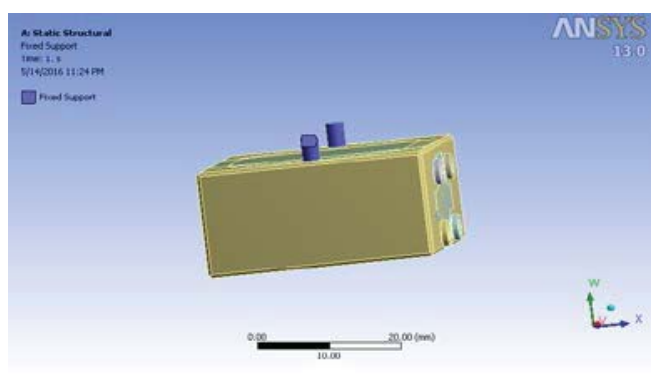

Figure 4 Boundary condition (fixed support) 


\section{Pressure applied}

20.601Mpapressure is applied in the port, which is showed in figure (red color).

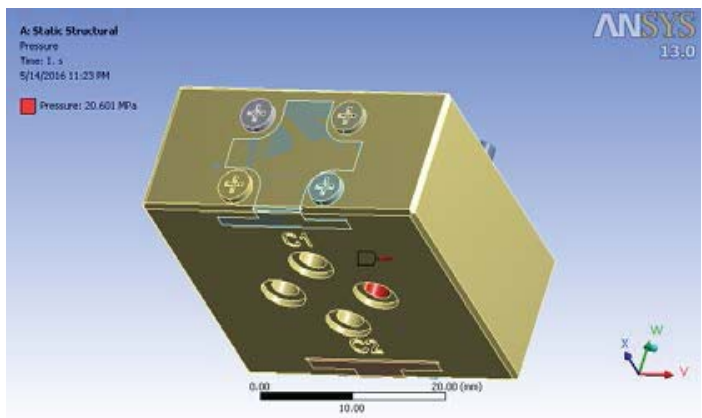

Figure 5 Pressure 20.16 MPa applied on the valve

Stress and Deformations

After applying the loads the stresses and deformations are induced. The loads are applied on the lines, nodes, key points or model. If the load is applied on the model it is transmitted to the nodes of the body.

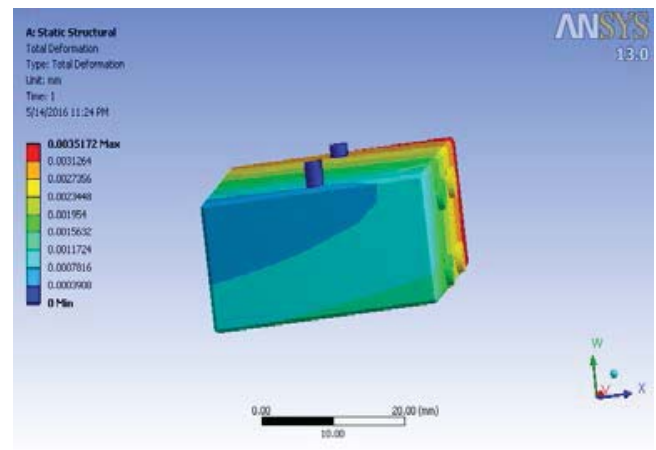

(a)

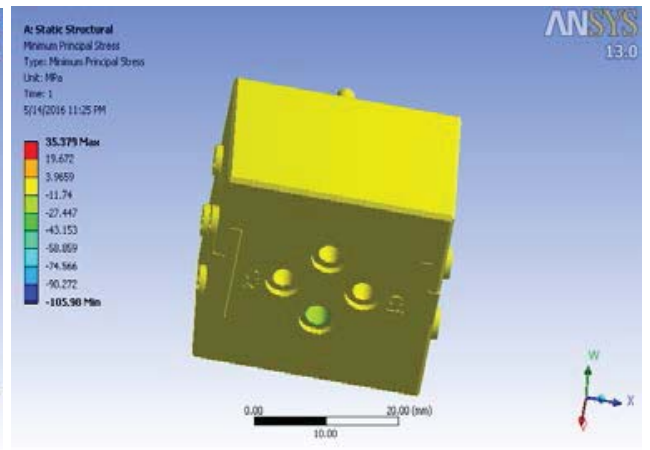

(b)

Figure 6 (a) Deformation of the valve (b) Stress induced in the valve

Results - Values are achieved from analysis

'Maximum stress' build up in the valve $=35.379 \mathrm{MPa}$

'Maximum deformation' induced $=0.0035172 \mathrm{~mm}$

The maximum stress $(35.379 \mathrm{MPa})$ induced in the valve is less than the yield stress of ductile iron that is $310 \mathrm{MPa}$.

\section{B. Analysis of valve after optimization}

Optimization is defined as minimizing or maximizing the function by selecting input values from given set and calculating value of the function. It is mainly depends on designers. And it also defined as maximize or minimize the product, reduce the production cost, enhance the quality. Minimizing the product size or introducing the less cost material it should not alter the performance of the model. It includes obtaining the extreme quality of the product at minimum production cost and introducing the new properties in current product. The customer wanted to get fine quality of material or product at most competitive cost existing in market.

The industry which gives the above qualities to customer needs will become winner. There are some problems in optimization they occur during minimizing or maximizing, these affects the performance of the model. Some changeable factors like geometry of model, loads applied on the model, materials used these may also have an effect on performance of the object. Optimization is done correspond to kind of material used, quantity of material used, time required for finishing of project and which kind of production method is used for optimization. Optimizing algorithm is the widely using method in engineering field, because ease of use and high speed computer. This method is mainly used where minimizing or maximizing the product. 


\section{Create the model}

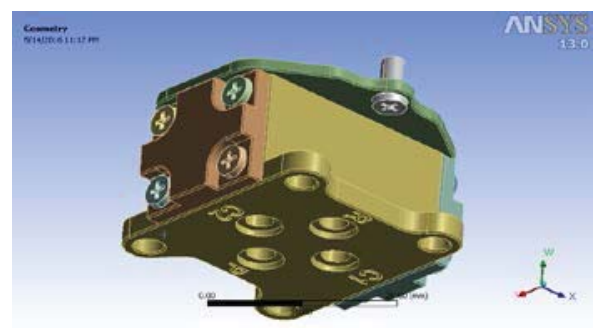

Figure 7 Geometry of the valve

Meshing

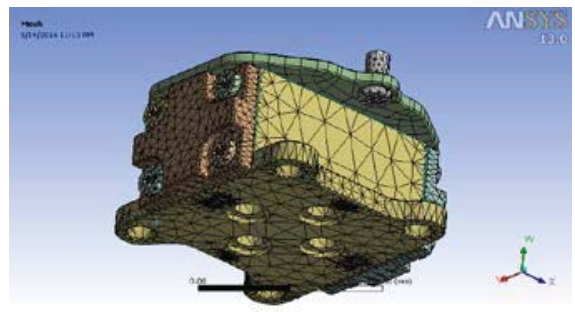

Figure 8 Meshing view of the valve

\section{Boundary conditions}

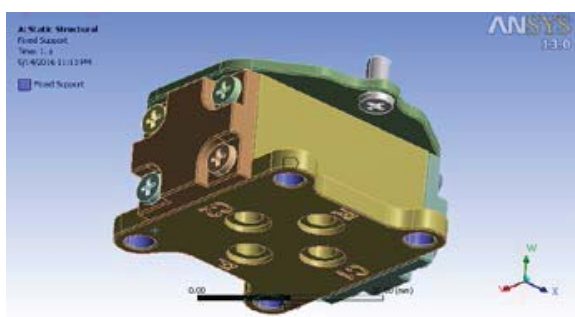

Figure 9 Boundary conditions (fixed support)

Pressure applied

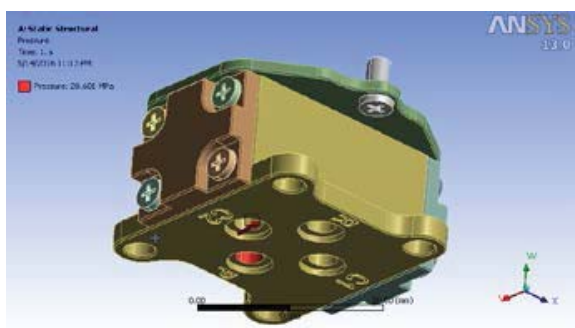

Figure 10 Pressure applied view

Stress and Deformations

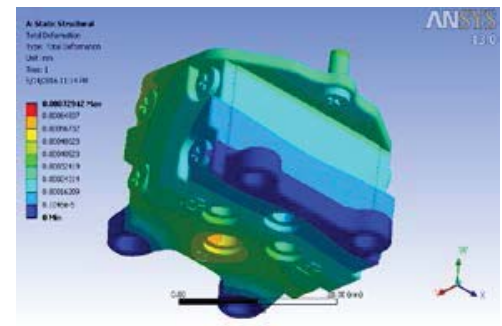

(a)

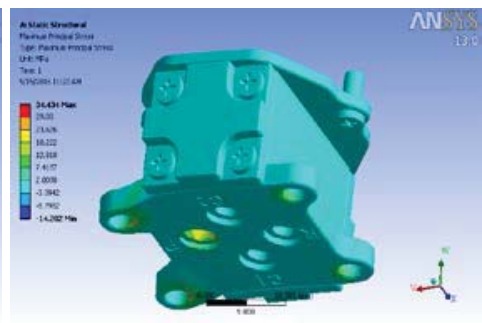

(b)

Results

Results which are achieved by the analysis after optimization.

'Maximum stress', developed in the valve $=34.434 \mathrm{MPa}$

'Maximum deformation' induced $=0.00072942 \mathrm{~mm}$

The 'maximum stress' (34.434 MPa) which is obtained from the analysis is below the yield stress of ductile iron that is $310 \mathrm{MPa}$. 


\section{Comparison of results}

\begin{tabular}{|c|c|c|c|}
\hline Sl No: & Parameters & Before 'Optimization' & After 'Optimization' \\
\hline 1 & Maximum stress & $35.379 \mathrm{MPa}$ & $34.434 \mathrm{MPa}$ \\
\hline 2 & Maximum deformation & $0.0035172 \mathrm{~mm}$ & $0.00072942 \mathrm{~mm}$ \\
\hline 3 & Weight & $141.81 \mathrm{gm}$ & $72.77 \mathrm{gm}$ \\
\hline 4 & Yield stress & $310 \mathrm{MPa}$ & $310 \mathrm{MPa}$ \\
\hline
\end{tabular}

The above comparison results illustrate that the weight of the valve is reduced by removing the unwanted material from the valve. The weight of the valve before optimization is $141.81 \mathrm{gm}$ and weight of the valve after optimization is $72.77 \mathrm{gm}$. Hence the total material reduced is $141.81-72.77=69.04 \mathrm{gm}=0.06904 \mathrm{~kg}$

The total amount of 'Cost reduction' $=0.06904 \times 75=$ Rs. 5.178 for one valve.

Expected monthly production rate is 5000 quantities,

Total cost saved per month $=5000 \times 5.178=$ Rs. 25890

Total cost saved per year $=25890 \times 12=$ Rs. 310680

\section{V.CONCLUSION}

Hydraulic valve is the component of the hydraulic system, it plays important role in the system. The analysis and optimization of the valve has been done with the help of ANSYS software.

Valve is designed and checked properly to achieve the requirements. Before optimization the mass of the valve was $141.81 \mathrm{gm}$ after optimization the mass of the valve is reduced to $72.77 \mathrm{gm}$. Optimization is done by removing the excess material in the valve. After optimization we got maximum stress induced in the valve is $34.434 \mathrm{MPa}$ which is less than the yield stress of the material. In additional decreases in size of valve leads to unsafe to the component, large deformations are induced. The total weight reduced is $69.04 \mathrm{gm}$. Hence the cost is saved by Rs. 310680 per year.

\section{REFERENCES}

[1] Lorenzo borello, Matteodalla, Giovanni Jacazio, Massimo sorli, "A Prognostic Model for Electrohydraulic Servovalves",Politecnico of Turin department of Aerospace Engineering, Torino, Italy.

[2] NiteshMondal, Dr.B.N.Datta, "A Study on electro hydraulic servo valve controlled by a two spool valve"Department of Aerospace Engineering and Applied Mechanics,Bengal Engineering and Science UniversityShibpur.

[3] M. R. Mokhtanadeh-Dehghan, N. Ladommatos, and T. J. Brennan, "Finite element analysis of flow in a hydraulic pressure valve.Department of Mechanical Engineering", Brunei University, Uxbridge, UK.

[4] [4] DeokarVinayak Hindurao1, D.S.Chavan2. "Optimization of 16 Plug Valve Body Using FEA And Experimental Stress Analysis Method", Rajarambapu Institute Of technology, Sakharale.

[5] Dr.K.H.Jatkar, Sunil S.Dhanwe, "Finite Element Analysis of Gate Valve", International Journal of Engineering and Innovative Technology (IJEIT), April 2013.

[6] Mr.V.D.Rathod, Prof.G.A.Kadam, Mr.V.G.Patil, "Design and Analysis of Pressure Safety Release Valve by using Finite Element Analysis", SKN Sinhgad Institute of Technology\& Science,Lonavala, University of Pune.

[7] Somashekhar SHiremath, "Delmoing and simulation of fluid structure interaction in jet pipe electrohydraulic servo valve", Precision engineering and instrumentation laboratory, Department of Mechanical Engineering, Indian Institute of Technology Madras.

[8] DusanGordic,MilunBabic,NebojsaJovicic,DobricaMilovanovic, "Effects of the Variation of Torque Motor Parameters onServovalve Performance".University of Kragujevac, Faculty of Mechanical Engineering in Kragujevac.

[9] Last accessed on (April 2 - 2016) www.hydraulic.com

[10] Last accessed on (May 01 - 2016) www.finite element method.com

[11] Last accessed on (May 08 - 2016) www.ductile iron alloy.com

[12] Last accessed on (May 03 - 2016) www.ANSYS.com

[13] Last accessed on (April 07 - 2016) www.electro hydraulic servo valve.com

[14] C. Hsu and J. Wu, "Multi-resolution Watermarking for Digital Images", IEEE Transactions on Circuits and Systems- II, Vol. 45, No. 8, pp. 1097-1101, August 1998.

[15] R. Mehul, "Discrete Wavelet Transform Based Multiple Watermarking Scheme", in Proceedings of the 2003 IEEE TENCON, pp. 935-938, 2003. 